\title{
The Design of Multi-Function Photoelectric Teaching Experimental Platform and Thinking of Curriculum Teaching Reform
}

\author{
Yaohua Deng, Jiayuan Chen, Liming Wu, Hui Chen, Guitang Wang \\ School of Information Engineering of Guangdong University of Technology, \\ Guangzhou Guangdong China \\ Email:dengyaohua@21cn.com
}

\begin{abstract}
A good photoelectric experimental teaching platform plays a very important role in the course of sensor, photoelectric engineering and photoelectric detection. With the development of information technology, it adds more and more new function for photoelectric teaching platform, which will bring great convenience to teaching undoubtedly. In view of this situation, in order to achieve a better teaching effect, the design of multi-function photoelectric teaching experimental platform will be put forward in this paper by taking the ARM as basic module, designing a new type of photoelectric teaching experimental platform with voice recognition and touch screen.
\end{abstract}

Keyword-Photoelectric detection; Photoelectric experimental teaching platform; Touch screen

\section{INTRODUCTION}

With the rapid development of social science and technology, photoelectric detection technology is not only widely used in advanced industrial countries in the world, but also has been widely used in the field of machinery, biomedicine, environment, metallurgy, chemistry, defense and others in our country [1]. A perfect photoelectric teaching experimental platform plays a very important role in the course of sensor, photoelectric engineering and photoelectric detection [2]. Constructing a multi-function optoelectronic teaching experimental platform based on the main content of photoelectric information acquisition, transmission, processing and information reproduction, in consideration for the needs of professional basic course experiment, can improve the efficiency of teaching at the same time, to fully mobilize the management level and the comprehensive effect of the classroom, which is constructing the photoelectric teaching experimental platform as an important base of personnel training really [3]. In view of this situation, this paper puts forward a design of multi-function photoelectric teaching experimental platform based on basic module in ARM to design a new photoelectric experimental teaching platform with voice recognition and touch screen.

\section{THE DESIGN SCHEME OF MULTI-FUNCTION PHOTOELECTRIC TEACHING EXPERIMENTAL PLATFORM}

New multi-function photoelectric teaching experimental platform based on ARM, peripherals for seven function modules (as shown in figure 1).

\section{A. Brightness, Color Temperature, Chroma Sensor Module}

Photoelectric receiver, made up of brightness sensor, color temperature sensor, chroma sensor and A/D converter which is connected to serial interface in ARM 11, will performs photoelectric conversion for optical information, temperature information and chroma information received and export to measuring circuit connected to external serial port to generate electricity information, and then through A/D converter, the processing results will show in ARM board screen after data storage, calculation and analysis by system on ARM board so as to realize the sensing function.

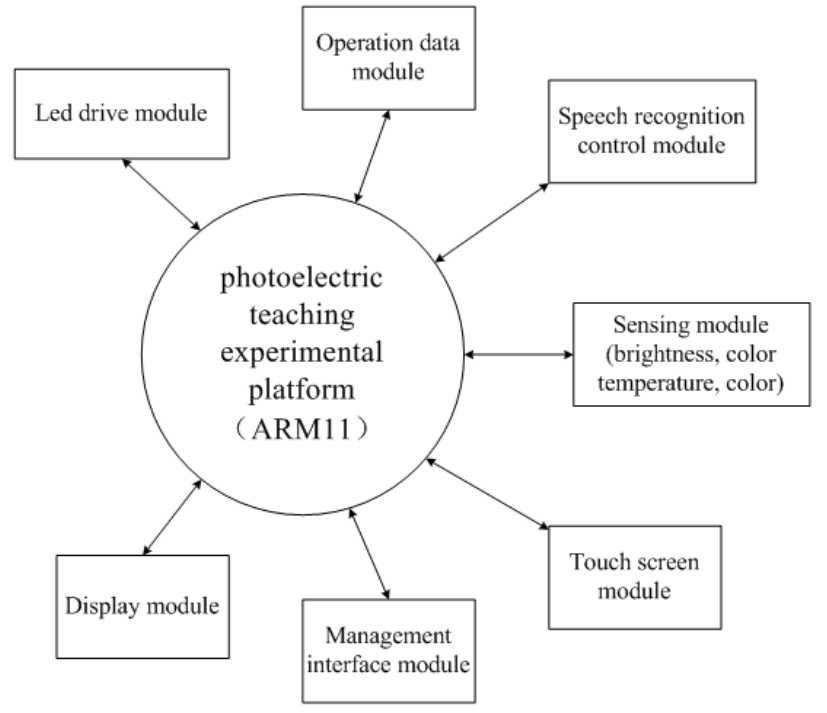

Fig 1. New multi-function photoelectric teaching experimental platform module structure diagram

\section{B. Speech Recognition Control Module}

Speech recognition, an important part of human-computer interaction, mainly complete audio input processing, audio data sampling, audio PCM data processing, pattern recognition and reasoning. Among them, data sampling can be implemented by specialized audio A/D, while audio PCM data processing, pattern recognition and reasoning can be done by high-performance ARM processor, in addition, audio D/A conversion can be used to output sound signal to complete audio playback.

LD3320, a "speech recognition" special chip, integrates 
voice recognition processor and corresponding external circuit including A/D converter, D/A converter, microphone interface, audio output interface, etc[4-5]. The chip is designed to focus on energy-saving and efficient and does not require external auxiliary chip such as Flash, RAM, etc, integrated in the existing products directly to realize speech recognition / voice / man-machine dialogue. In addition, the list of identified key words can be arbitrary dynamic editing. LD3320 voice control development board will determine the teaching need to command mode after sampling voice and send the data to Lower machine.

\section{LED Driver Module}

SDMX5124, a single control chip with high integration, low power consumption, full-color LED lighting, taking original synchronous DMX512 single LED lighting control system, make the cascade control of LED lamp flexible and simple, therefore, this LED driver chip is used adopted. SDMX5124 is made up of communication module realizing the sending and receiving circuit of single wire transmission and PWM control module controlled by three PWM dimming control circuit which is four bits for every, gray level 16, achieving 4096 kinds of color. The LED driver module on SDMX5214 chip is controlled to achieve different pattern of LED lighting changes.

\section{Other Modules}

According to the design requirements, multi-function photoelectric teaching experimental platform also has a touch screen module, operation data module, display module and data management interface module and so on, achieving touch screen teaching, data analysis and calculation of teaching, the display of teaching interface and teaching effect, the management of photoelectric teaching experimental platform, and other functions respectively.

\section{DESIGN OF MAIN FUNCTION MODULE}

\section{A. Design of Sensing Function Module}

In photoelectric conversion circuit, photoelectric sensor converts are used to transform optical signal to electrical signal. The circuit is shown in figure 2 (a).

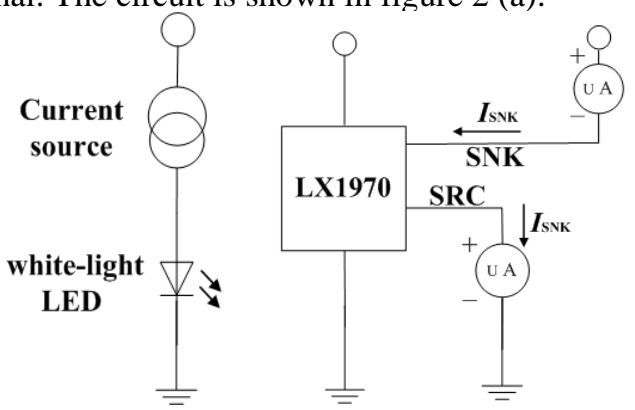

Fig 2. Photoelectric signal conversion diagram

The measurement circuit composed of visible light brightness sensor LX1970 is shown in figure 2 (b) [6]. A visible light send to the light source which is made up of Ucc, current source and white LED light, is received by LX1970, converting visible light into corresponding current signal. And a microammeter is set series in SNK end and in SRC end each, measuring current ISNK and ISRC respectively, which value read from microammeter will reflect brightness level.

PT100 Temperature sensor is chosen as temperature sensor parts included in sensing module in this design. PT100, a kind of platinum thermal resistance sensor with good stability and linearity, can work in $-200^{\circ} \mathrm{C}$ to $650^{\circ} \mathrm{C}$, and this circuit chooses to work in the range of $-19^{\circ} \mathrm{C}$ to $500^{\circ} \mathrm{C}$ [7]. The whole circuit is divided into two parts; the one is sensor preamplifier circuit and the other is $A / D$ conversion, display, control and nonlinear correction software, etc in the ARM board. The diagram of preamplifier section is shown in figure 3 .

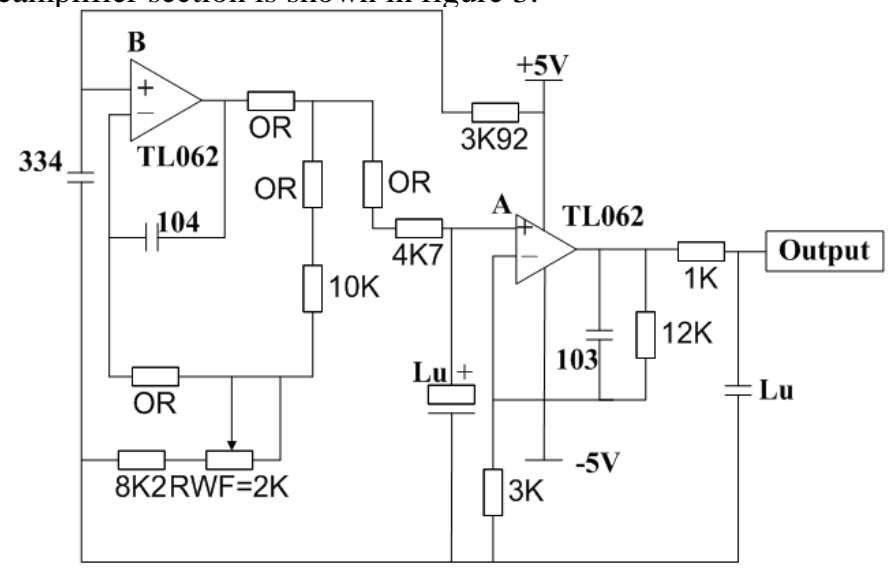

PT100 input: $100-280.98 \Omega$

Fig 3. The principle diagram of sensor preamplifier

The sensor access is very simple, connecting to PT100 by a $3 \mathrm{k} 92$ resistor from power supply terminal on system, which will cause serious nonlinear problems, but it will simplify the access way of sensors when software correction algorithm on mcu become the backstop.

\section{B. Design of Speech Recognition Module}

The design of core system module adopts Linux system. Because Linux 2.6.13 contains with Alsa (Advanced Linux (Architecture) drive engineering, providing audio AD/DAWM8731L drives, in order that developers can write applications based on the audio data input and output sampled[8-9]. Among them, speech recognition program flow and interrupt process are shown in figure 4(a) and figure 4(b). 


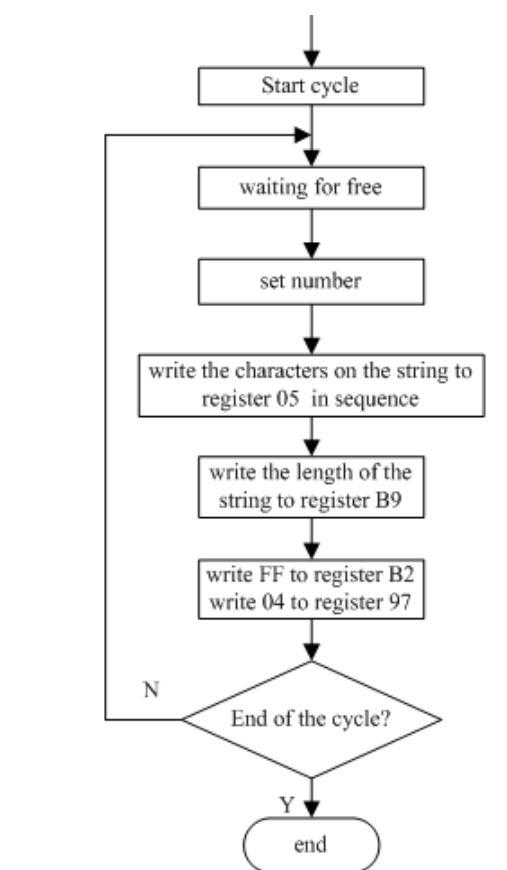

(a) Speech recognition program flow diagram

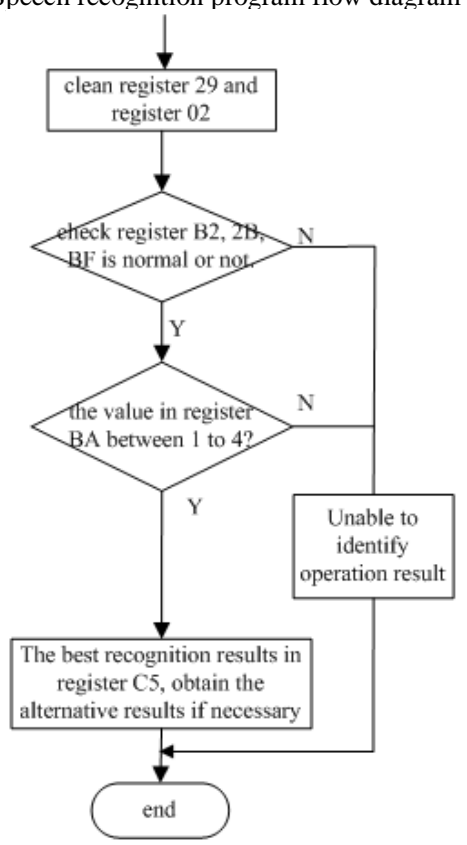

(b) Interrupt program flow diagram

Fig 4. Speech recognition module program design flow diagram

\section{Design of LED Driver Module}

LED data control transmission adopts the control mode of clock shift latch, taking three root signal lines to realize shift latch, they are DATA, CLK and MCLKI respectively. With this control mode, internal clock is derived from the master clock input (MCLKI), which can be obtained from SDMX5124 or LED lighting controller. For the format of control data, SDMX5124 is used in cascade control mode, which passing a data frame, it refreshes the color from a control line of RGB three PWN channels on SDMX5124 at the same time. The length of data frame is as follow:

Boot code $(16$ bits $)+$ Control data $(12 \times N$ bits $)+$ Stop code $(16$ bits $)=16+12 \times N+16$ bits

Among them, $\mathrm{N}$ is for the number of SDMX5124 on the line. When the port of SDMCX5124 works in clock shift latch control mode, the signal of MCLK I/O and CLK I/O are needed. CLK signal follows the synchronous relationship that taking count on rising edge time and taking sample on fall edge time.

Notice: because the control data of SDMX5124 is encoded before transmission, a CPLD chip may be used as chip controller provided from YDSCO Company to complete communication code, not transparent transmission.

\section{TEST ON MULTI-FUNCTION PHOTOELECTRIC TEACHING EXPERIMENTAL PLATFORM FUNCTION MODULE}

\section{A. Test on Speech Function Module}

The response of testing on speech must specify optional responsive entry for pattern recognition firstly, run the main program and specify one, speech recognition effect is observed under different distance as shown in table1.

\section{B. Test on Temperature Sensor Module}

According to the parameters of PT100, within the interval from $0{ }^{\circ} \mathrm{C}$ to $500^{\circ} \mathrm{C}$, resistance value may be from 100 to $2801 \Omega$, and the output voltage obtained under measuring different temperature environments is shown in table 2 .

TABLE I. SPEECH RECOGNITION CONTROL EFFECT

\begin{tabular}{|c|c|c|c|}
\hline \multirow{2}{*}{ time } & \multicolumn{3}{|c|}{ distance } \\
\cline { 2 - 4 } & inside 5 meters & inside 8 meters & $\begin{array}{l}\text { outside 8 } \\
\text { meters }\end{array}$ \\
\hline 1 & yes & yes & no \\
\hline 2 & yes & no & yes \\
\hline 3 & yes & yes & no \\
\hline 4 & yes & yes & no \\
\hline accuracy rate & $100 \%$ & $75 \%$ & $25 \%$ \\
\hline
\end{tabular}

TABLE II. THE OUTPUT VOLTAGE CONTRAST UNDER DIFFERENT TEMPERATURE ENVIRONMENTS TABLE

\begin{tabular}{|c|c|c|}
\hline $\begin{array}{c}\text { Temperature( } \\
\left.{ }^{\circ} \mathbf{C}\right)\end{array}$ & $\begin{array}{c}\text { PT100 resistance } \\
\text { value( } \mathbf{\Omega})\end{array}$ & $\begin{array}{c}\text { Terminal Voltage of } \\
\text { the sensor(mV) }\end{array}$ \\
\hline 0 & 100.00 & 124.38 \\
\hline 1 & 100.39 & 124.80 \\
\hline 50 & 119.40 & 147.79 \\
\hline 100 & 138.51 & 170.64 \\
\hline 150 & 157.33 & 192.93 \\
\hline 200 & 175.86 & 214.68 \\
\hline 250 & 194.10 & 234.90 \\
\hline 300 & 212.05 & 256.59 \\
\hline 350 & 229.72 & 276.79 \\
\hline 400 & 247.09 & 296.48 \\
\hline 450 & 264.18 & 315.69 \\
\hline 500 & 280.98 & 334.42 \\
\hline
\end{tabular}

\section{Test on LED Drive Module}

The testing principle on LED display control module is: in the case of ensuring the startup code, sending code, 
ending code are correct, giving gradually variation $\mathrm{R}(0 \times \mathrm{fO0}), \mathrm{G}(0 \mathrm{x} 0 \mathrm{f0}), \mathrm{B}(0 \mathrm{x} 00 \mathrm{f})$ three-primary colors to $\mathrm{a}$ cascade of 12 lamp beads, when the color display is normal, corresponding RGB table can be filled in a variety of other colors. After verification, the corresponding relationship between standard RGB table and SDMX5124 RGB table is as table 3 .

\section{$\mathrm{V}$ EMPLOYING SITUATION AND TEACHING THINKING OF PHOTOELECTRIC EXPERIMENTAL TEACHING PLATFORM}

Multi-function photoelectric experimental teaching platform based on ARM board, peripheral several other new features with the characteristics of light, machine, electricity and calculation, can satisfy all kinds of photoelectric sensor principle and application in the

TABLE III. CORRESPONDING RELATIONSHIP BETWEEN STANDARD RGB AND SDMX5124 RGB TABLE

\begin{tabular}{|c|c|c|}
\hline item & standard RGB & SDMX5124 RGB \\
\hline 1 & $0-15$ & 0 \\
\hline 2 & $16-31$ & 1 \\
\hline 3 & $32-47$ & 2 \\
\hline 4 & $48-63$ & 3 \\
\hline 5 & $64-79$ & 4 \\
\hline 6 & $80-95$ & 5 \\
\hline 7 & $96-111$ & 6 \\
\hline 8 & $112-127$ & 7 \\
\hline 9 & $128-143$ & 8 \\
\hline 10 & $144-159$ & 9 \\
\hline 11 & $160-175$ & A \\
\hline 12 & $176-191$ & b \\
\hline 13 & $192-211$ & c \\
\hline 14 & $212-227$ & d \\
\hline 15 & $228-239$ & f \\
\hline 16 & $240-255$ & multi-function \\
\hline
\end{tabular}

experimental requirements. Adopting multi-function teaching experimental platform, teachers can teach and operate on the screen with functional diversity and convenient operation, making students visually study the application and corresponding operations, providing more opportunities for students to learn independently at the same time, which making them more faster and intuitive to get knowledge. At present, the development of economy is asking higher requirement on talent, while multi-function photoelectric teaching experimental platform can make students learn more knowledge in a shorter time, improving the efficiency of teachers' teaching and students' receiving, which not only meet the technical development trend, but also give the attempt to reform on some courses.

\section{ACKNOWLEDGEMENT}

This work is partially supported by 2013 university-level education teaching reform project of Guangdong University of Technology (2013ZY008). Thanks for the help.

\section{REFERENCES}

[1] YE Mei, Inquire into Platform Build for Opto -electric Test Teaching Experiment of Instrumentation Speciality[J], LABORATORY SCIENCE, 2008,(4):105-108.

[2] Li Dangjuan, Cultivating Engineering Innovation Ability Based on Optoelectronic Experimental Platform[J], Value Engineering, 2012,31(7):69.

[3] CHEN He-ning, FAN Hong, QIAN Chen, etc, Research and practice of optoeletronic information laboratory construct[J], OPTICAL TECHNIQUE, 2007,33(z1):307-308.

[4] Jin Xin, Tian Ben, Que Dashun, Design of Voice-Controlled System Based on LD3320[J], Computer and Information Technology, 2011,19(6):22-25.

[5] Hong Jiaping, Application of Embedded Speech Recognition System Based on LD3320[J], Microcontrollers \& Embedded Systems, 2012,12(2):47-49.

[6] Meng Zhiyong, Sha Zhanyou, An Guochen, Integrated Brightness Sensor Emulating the Human Eye[J], INTERNATIONAL ELECTRONIC ELEMENTS, 2004,(6):26-28.

[7] ZHANG Xiutai, HU Xuehui, ZHAI Yafang, etc, The Design and Experimental Study of High Precise Temperature Acquisition System Based on PT100[J], CHINESE JOURNAL OF SENSORS AND ACTUATORS, 2010,23(6):812-815.

[8] Liu Shi, Li huaizhou, Zhao Xuegong, ALSA Audio Programming Under the Linux Platform[J], COMPUTER CD SOFTWARE AND APPLICATIONS, 2011,(6):175.

[9] Ding Yong, Zhou Yu, Du Sidan, ON LINUX 2.6 BASED EMBEDDED ASOC AUDIO DRIVER AND ITS IMPLEMENTATION[J], CHINESE JOURNAL OF SENSORS AND ACTUATORS, 2010,27(4):267-273 
